\title{
Molecular and phenotypic characterization of the alternative seasonal growth habit and flowering time in barley (Hordeum vulgare ssp. vulgare L.)
}

Article

Accepted Version

Cockram, J., Horsnell, R., Soh, E.-h., Norris, C. and O'Sullivan, D. (2015) Molecular and phenotypic characterization of the alternative seasonal growth habit and flowering time in barley (Hordeum vulgare ssp. vulgare L.). Molecular Breeding, 35 (8). 165. ISSN 1380-3743 doi: https://doi.org/10.1007/s11032-015-0359-5 Available at https://centaur.reading.ac.uk/41237/

It is advisable to refer to the publisher's version if you intend to cite from the work. See Guidance on citing.

Published version at: http://dx.doi.org/10.1007/s11032-015-0359-5

To link to this article DOI: http://dx.doi.org/10.1007/s11032-015-0359-5

Publisher: Springer Verlag

All outputs in CentAUR are protected by Intellectual Property Rights law, including copyright law. Copyright and IPR is retained by the creators or other copyright holders. Terms and conditions for use of this material are defined in the End User Agreement. 


\section{www.reading.ac.uk/centaur}

\section{CentAUR}

Central Archive at the University of Reading

Reading's research outputs online 
Molecular and phenotypic characterization of the alternative seasonal growth habit and flowering time in barley (Hordeum vulgare ssp. vulgare L.)

James Cockram . Richard Horsnell . Eun-hee Soh .

Carol Norris . Donal M. O’Sullivan

J. Cockram, R. Horsnell,E. Soh,C. Norris, D. M. O’Sullivan

John Bingham Laboratory, National Institute of

Agricultural Botany (NIAB), Huntington Road,

Cambridge CB3 OLE, UK

e-mail: james.cockram@niab.com

Present Address:

E. Soh

Korea Seed and Variety Service, Suwon, South Korea

Present Address:

C. Norris

Bayer Crop Science, Cambridge Science Park,

Cambridge CB4 0WB, UK

Present Address:

D. M. O'Sullivan

University of Reading, Reading RG6 6AR, UK 


\begin{abstract}
:
Barley can be classified into three major agronomic types, based on its seasonal growth habit (SGH): spring, winter and alternative. Winter varieties require exposure to vernalization to promote subsequent flowering and are autumn-sown. Spring varieties proceed to flowering in the absence of vernalization and are sown in the spring. The 'alternative' (also known as 'facultative') SGH is only loosely defined and can be sown in autumn or spring. Here, we investigate the molecular genetic basis of alternative barley. Analysis of the major barley vernalization (VRN-H1, VRN-H2) and photoperiod (PPD-H1, PPD-H2) response genes in a collection of 386 varieties found alternative SGH to be characterized by specific allelic combinations. Spring varieties possessed spring loci at one or both of the vernalization response loci, combined with long-day nonresponsive ppd-H1 alleles and wild-type alleles at the short-day photoperiod response locus, PPD-H2. Winter varieties possessed winter alleles at both vernalization loci, in combination with the mutant ppd-H2 allele conferring delayed flowering under short-day photoperiods. In contrast, all alternative varieties investigated possessed a single spring allele (either at VRN-H1 or at VRN-H2) combined with mutant ppd- $\mathrm{H} 2$ alleles. This allelic combination is found only in alternative types and is diagnostic for alternative SGH in the collection studied. Analysis of flowering time under controlled environment found alternative varieties flowered later than spring control lines, with the difference most pronounced under short-day photoperiods. This work provides genetic characterization of the alternative SGH phenotype, allowing precise manipulation of SGH and flowering time within breeding programmes, and provides the molecular tools for classification of all three SGH categories within national variety registration processes.
\end{abstract}

Keywords: Flowering time, Vernalization Requirement,Triticeae,Diagnostic genetic markers, Crop adaptation, Marker assisted selection 


\section{Introduction}

Barley (Hordeum vulgare ssp. vulgare L.) was one of the first cultivated grains and is currently the fourth most important cereal in the world, in terms of both quantity produced and area of cultivation. Flowering time is a critical component of barley adaptation to agricultural environment, as alignment of crop development with favourable environmental conditions helps maximize grain yield (Cockram et al. 2007a). Wild barley (H. vulgare ssp. spontaneum C. Koch) possesses a winter seasonal growth habit (SGH), requiring exposure to prolonged periods of low temperature (vernalization, typically 6-8 weeks at $4{ }^{\circ} \mathrm{C}$ ) for competence to flower during inductive conditions the following summer. In the wild, this response allows vegetative growth to be established prior to the spring and prevents the development of sensitive floral organs over winter months, thus avoiding low-temperature damage. Cultivated barley varieties which retain this ancestral response are classified as possessing a 'winter' SGH. Four major genetic loci are known to control a large proportion of flowering time variation in barley. These are the vernalization response loci VERNALIZATION-H1 (VRN-H1) and VRN-H2, and the photoperiod response loci PHOTOPERIOD-H1 (PPD-H1) and PPD-H2 (reviewed by Bentley et al. 2013). VRN-H1 is encoded by the MADS-box transcription factor HvBM5A which shows homology to the Arabidopsis meristem identity gene APETALA 1 (AP1), although functionally it is more similar to the Arabidopsis gene, FRUITFUL (FUL). In barley, deletions or insertions within VRN-H1 intron I that disrupt putative cisregulatory regions are thought to confer dominant spring alleles, which result in VRN-H1 expression and subsequent floral transition in the absence of vernalization (Cockram et al. 2007b, c, 2011; Sz \}ucs et al. 2007; Hemming et al. 2009; Trevaskis 2010). At the VRN-H2 locus, deletion of three closely linked genes (ZCCT-Ha, Hb, Hc) is thought to be responsible for the creation of recessive vernalization insensitive vrn-H2 alleles (Yan et al. 2004; Karsai et al. 2005; Distelfeld et al. 2009). Cereal ZCCT genes encode a zinc-binding domain and a CCT domain and have evolved as part of a chromosomal duplication event that predates the divergence of cereal species (Cockram et al. 2010a). Based on analysis of CCT motifs, they belong to a family of plant flowering time genes belonging to the CONSTANS-like Group I clade (Cockram et al. 2012a), which also contains the rice flowering time gene Ghd7. Truncation/deletion of Ghd7 removes floral delay under long-day (LD) photoperiods and is one of the key variations which have allowed rice to grow in temperate LD agricultural environments (Xue et al. 2008). Similarly, VRN-H2 is thought to repress flowering under LDs, as it shows little or no expression in SD photoperiods (Trevaskis et al. 2006; Turner et al. 2013). Current flowering time models hypothesize that VRN-H2 represses the floral promoter FLOWERING LOCUS T 1 (FT1), with VRN-H1 repressing VRN-H2 expression in vernalization sensitive accessions under LDs (Trevaskis 2010). VRN-H1 is gradually upregulated during vernalization, repressing VRN-H2 and allowing expression of FT1 under LDs. To confer a winter SGH, barley varieties must carry wild-type winter alleles at both VRN-H1 and VRN$\mathrm{H} 2$, while spring varieties must possess vernalization insensitive spring alleles at one or both loci (Laurie et al. 1995). The PPD-H1 locus controls flowering in response to LDs. It is encoded by gene 
belonging to the PSEUDO RESPONSE REGULATOR (PRR) gene family (Turner et al. 2005), which in Arabidopsis acts close to the central oscillator. In barley, the photoperiod insensitive ppd-H1 allele is thought to be due to a nonsynonymous G/T mutation within the CCT domain (Turner et al. 2005). Plants carrying the ppd-H1 allele (T nucleotide) are delayed in flowering under LD, allowing them to take advantage of the long growing seasons prevalent in north-west Europe. The PPD-H2 locus modulates flowering under short-day (SD) photoperiods and is thought to be encoded by the FT-like gene, HvFT3 (Faure et al. 2007). Complete or partial deletion of HvFT3 is associated with recessive ppd-H2 alleles that result in delayed flowering under SDs.

During barley domestication, early farmers selected types that lack a vernalization requirement and so are able to progress to flowering in the absence of vernalization (Jones et al. 2011). These possess a 'spring' SGH, germinate and flower in the same year. This selection has led to two largely distinct breeding pools, with associated partitioning of genome-wide genetic diversity (Cockram et al. 2008, 2012b). However, a third classification exists: the 'alternative' SGH. Alternative varieties are only loosely described, but can be used agronomically either as spring or as winter types. At the molecular level, classification of alternative types has received little attention and has been variously described. For example, von Zitzewitz et al. (2005) described an alternative (also termed 'facultative') variety as containing a winter vrn-H1 allele combined with a spring vrn- $\mathrm{H} 2$ allele. The resulting plant would likely retain the frost tolerance loci linked to VRN-H1 on the long arm of chromosome $5 \mathrm{H}$, while displaying a spring (vernalization non-responsive) phenotype conferred by vrn- H2 alleles. Similarly, others describe alternative varieties as carrying "only a modest vernalization response" (Szucs et al. 2007), delaying flowering by only a few days, which can again be predicted by known allele combinations at VRN-H1 and VRN-H2 (Karsai et al. 2005). During the process of awarding Plant Breeders' Rights, new barley submissions are classified as belonging to one of the three SGH classes according to internationally recognized Distinct Uniform and Stable (DUS) protocols, as outlined by the Union for the Protection of Varieties (UPOV) (Jones et al. 2013). Within the DUS system, alternative types are defined as lines that flower later than spring lines in the absence of vernalizing temperatures, and are based on field assessment of flowering time. For DUS purposes, the scoring of this characteristic currently involves planting out significant areas of submitted winter and alternative varieties in spring time in order to confirm their seasonal growth habit (SGH). Winter varieties do not flower at all, and since the material does not produce heads or grains, the trial is not used to score any other characters. A molecular test for the vernalization characteristic in barley would serve to demonstrate to the international community the viability and advantages of using a molecular approach to assess functional traits of relevance to DUS. It is also clearly attractive as a direct replacement for the existing field trials on a cost- benefit basis. Furthermore, molecular characterization of the alternative SGH will allow breeders to track and combine relevant flowering time alleles for the development of new alternative varieties. This study uses a collection of 386 barley varieties to identify the flowering time haplotypes diagnostic for alternative $\mathrm{SGH}$, as well as 
for spring and winter types, and shows that alternative varieties flower later than spring types under both LD and SD photoperiods.

\section{Methods}

\section{Barley germplasm and growth conditions}

Six alternative UK barley varieties were sourced from germplasm stored at NIAB. An additional 380 spring and winter UK varieties were sourced, as previously described (Cockram et al. 2010b) (Supplementary Table 1). Ten varieties were selected for investigation of flowering time under controlled environment conditions (where known, application for protection [AFP] numbers is shown in brackets): alternative varieties, Gaelic (2/1117), Novetta, SW Alison (2/ 1788), 52B4 (2/1797) and BR5593C3 (2/2159); winter varieties, Igri (2/129), Tempo (2/1170) and Express (2/ 894); spring varieties, Felicie (2/1091, early spring control), Indola (2/1874, late spring control) and Rebecca (2/1871). Seeds were germinated on moist filter paper for $24 \mathrm{~h}$ at 4 "C, and the resulting seedlings grown in one-litre pots filled with M2 compost. Five replicates were grown per variety, with 10 replicates grown for the early (Felicie) and late (Indola) spring control varieties. Plants were arranged in a randomized bock design and grown for 140 days under controlled environment conditions, with day/night temperatures of $20 / 18{ }^{\circ} \mathrm{C}$. Long-day and short-day experiments received 16 and $12 \mathrm{~h}$ of light, respectively. Plant developmental stages were recorded according to Zadok's growth stage (GS). Flowering time was recorded as date of awn emergence (GS 47). Apical meristems of all plants that had not flowered by the end of each SD and LD experiment were dissected using a stereomicroscope and imaged using a mounted camera.

\section{DNA extraction, genotyping and sequencing}

Genomic DNA was extracted from leaf material using the DNeasy Kit (Qiagen). DNA quality was assessed using a Nanodrop 200 spectrophotometer (Thermo Scientific) and diluted to a final concentration of $10 \mathrm{ng} / \mathrm{ll}$. VRN-H1 haplotypes were determined using the diagnostic multiplex PCR/agarose gel multiplex assay described by Cockram et al. (2009), as well as the single nucleotide polymorphisms (SNPs)/simple sequence repeats (SSRs)/insertion-deletions (InDels) described by Cockram et al. (2007b) (Fig. 1). VRN-H1 intron I from the variety Eminant was investigated using primer pairs that tile across the region, as described by Cockram et al. (2007b). VRN-H1 sequencing was performed by direct sequencing of PCR products using BigDye Kit v3.5 (Applied Biosystems) in $10 \mathrm{ll}$ sequencing reactions using the primers and methods described by Cockram et al. (2007b) on a 3730 DNA Analyser (Applied Biosystems). Sequence outputs were processed using sequence analysis (Applied Biosystems), analysed using the Vector NTI Advance package v10.1.1 (Invitrogen) and manipulated using GENEDOC v2.6 (http://www.nrbsc.org/gfx/genedoc/). DNA and protein alignments were performed using CLUSTALW (Thompson et al. 1994) with additional manual 
adjustment. Genomic sequences were submitted to GenBank under accessions KT247893 to KT247898 (Supplementary Table 2). Presence/absence of the three ZCCT-H candidate genes underlying the VRNH2 locus was genotyped using the PCR/agarose gel assay described by Karsai et al. (2005). The nonsynonymous T3081/G SNP in the CCT domain of PPD-H1 (Turner et al. 2005) was genotyped by direct sequencing of PCR products amplified using primers PPD9F (50AACACCAATAACGGGAGCAC-30) and PPR9R (50 CCGGCATGTTCTATGGTAGG-30). The presence/absence of the HvFT3 candidate gene at the PPD-H2 locus was genotyped using primers described by Faure et al. (2007) that amplify an 874-bp product when HvFT3 is present, with the inclusion of an additional internal positive control using primers BM5A1intF (50TCCCAAGAAAACTTGAACAACACCAG-30) and BM5A2intR (50 GGTATTAGGTTACATCATTCGACCA-30), which additionally assays for the 42-bp insertiondeletion (InDel) in VRN-H1 intron 1 (resulting in amplicons of 616 and 574 bp, respectively) (Fig. 2).

\section{Results}

\section{Genotyping major flowering time loci in spring, winter and alternative barleys}

We previously showed that SGH for spring and winter barley can be predicted by their multi-locus haplotypes at VRN-H1 and VRN-H2 (Cockram et al. 2007b, 2009). Here, we hypothesize that differences in haplotypes at the vernalization loci VRN-H1 and VRNH2 and the photoperiod response loci PPD-H1 and PPD-H2 largely determine the differentiation in flowering time of alternative varieties from winter and spring forms. Genotyping VRN-H1 and VRN-H2 in the $380 \mathrm{UK}$ winter and spring varieties (Supplementary Table 1) found all winter accessions to possess winter alleles at both loci, as predicted by the epistatic interaction between the two loci (Table 1). The majority of winter varieties $(95 \%)$ were found to possess the winter haplotype 1A allele. The remaining 11 varieties possessed the $5 \mathrm{C}$ haplotype which contains a $0.5 \mathrm{~kb}$ deletion within the Lolaog LTR in intron 1 (as well as numerous other SNPs) and has previously been associated with a weak vernalization requirement (Cockram et al. 2007b; Hemming et al. 2009). Winter lines varied for alleles at PPD-H1, with the majority (52\%) possessing the wild-type LD photoperiod-responsive Ppd-H1 allele, with a G nucleotide at position +3081 (Table 1). The remaining $48 \%$ possessed a $\mathrm{T}$ nucleotide at position 3081, thought to confer the non-responsive ppd-H1 allele (Turner et al. 2005). Finally, all but three winter varieties (Adonis, Gaulois and Tempo) show a deletion of the PPD-H2 candidate gene, HvFT3. Spring Vrn-H1 alleles and LD photoperiod non-responsive ppd-H1 alleles were found in all of the 170 spring varieties investigated. However, while the majority of spring varieties carried spring vrn- $\mathrm{H} 2$ alleles, $18 \%$ were found to possess winter alleles. All but one spring variety (Rebecca) were predicted to possess wild-type Ppd-H2 alleles. Thus, with the exception of the four lines highlighted above, spring and winter varieties were found to be partitioned for the presence of Ppd- $\mathrm{H} 2$ and ppd$\mathrm{H} 2$ alleles, respectively. Using the two multiplex assays for VRN-H1 and VRN-H2, five of the six 
alternative varieties were predicted to be phenotypically spring. In addition, all six alternative lines carried a deletion of HvFT3, indicating that they carry the ppd-H1 allele (found in $99 \%$ of winter varieties screened here) previously shown to delay flowering under SDs (Laurie et al. 1995; Faure et al. 2007). Although alternative varieties showed specific allelic distributions at VRN-H1, VRN-H2 and PPD-H2, genotypic evaluation of PPD-H1 showed LD-responsive and non-responsive alleles to vary between alternative lines, with the wild-type Ppd-H1 allele found in two of the six alternative lines investigated (Novetta and 52B4).

\section{Flowering time under SD and LD photoperiods}

Following the identification of specific VRN-H1/VRNH2/ PPD-H2 multi-locus haplotypes characteristic for spring/winter/alternative SGH, ten varieties with varying multi-locus haplotypes were selected for phenotypic evaluation of flowering time under LD and SD photoperiods (Fig. 3). These included control winter and spring varieties with varying allelic combinations at the four major flowering time loci. The three winter control lines consisted of Igri, which carries the standard multilocus configuration at the four major flowering time loci genotyped [vrn-H1 (haplotype 1A), Vrn-H2, Ppd-H1, ppd-H2], Tempo (differing to Igri by the presence of a dominant Ppd- H2 allele) and Express (differing to Igri by the presence of the 'weak' haplotype 5C winter allele at VRN-H1). Additionally, three spring control varieties were evaluated, including two varieties used as controls within DUS phenotypic evaluation of flowering time: Felicie, the early flowering DUS spring control, which possesses the standard spring multilocus haplotype (Vrn-H1, vrn-H2, ppd-H1, Ppd-H2), and Indola, the late flowering DUS control, which differs to Felicie by the presence of a dominant late flowering Vrn-H2 allele. In addition, the spring variety Rebecca was included, which differs from the early flowering control Felicie (and all other spring varieties investigated) by the presence of a late flowering ppd-H2 allele. Grown alongside the control varieties were the alternative varieties Gaelic (2/1117), Novetta, SW Alison (2/1788), 52B4 (2/1797), BR5593C3 (2/2159), all of which possessed one spring VRN allele in combination with a recessive ppd-H2 allele that delays flowering under SDs. Under LD photoperiods in the absence of vernalization, two of the three winter varieties remained vegetative by experiment end, with Tremois (GS 32) more advanced relative to Igri (GS 31), although meristem development for both was at the double ridge stage (Fig. 3b). The winter variety Express flowered at $87 \pm 4.2$ days, significantly later than the late spring control variety, indicating that it possesses a weak spring SGH. All other varieties flowered, with the early (Felicie) and late (Indola) spring control lines flowering at $67 \pm 0.8$ and $75 \pm 4.0$ days, respectively. The five alternative varieties showed a range of mean flowering times, ranging from $52 \pm 0.4$ (52B4) to $95 \pm 4.0$ (BR5593C3). Alternative lines with the LD responsive Ppd-H1 allele (Novetta, 52B4) flowered significantly earlier than the early spring control, while those with the non-responsive allele flowered along with the late spring control, or significantly after (BR5593C3). Rebecca, the only spring variety found to possess a mutated ppd-H2 allele, flowered after the late DUS spring control ( $77 \pm 4$ days), although this 
difference was not significant. Under SDs, development was delayed for all varieties, in comparison with LDs (Fig. 3a). The winter varieties Igri and Tremois were developmentally most delayed, as determined by GS and meristem dissection. In contrast, the early control Felicie (flowered at $104 \pm$ 11.8 days) and late spring control Indola (GS 45) controls were the most advanced, followed by the anomalous spring variety Rebecca (GS 43). The five alternative varieties were considerably later in their development than the spring lines, ranging between GS 37 (SW Alison, Gaelic) and GS 31 (Novetta, BR5593C3). This difference was also seen in apical development, with alternative lines at GS 31, 33 and 37 all showing inflorescence development.

\section{VRN-H1}

To further investigate VRN-H1 genetic variation in alternative varieties, seven polymorphic features (six SNPs and one SSR), previously used by Cockram et al. (2007b) to assign VRN-H1 haplotypes, were genotyped (Table 2). The SNPs, located in the promoter region (SNP1, SNP2 and SNP3) and 30 end of the gene (SNP4, SNP5 and SNP6), were identified by direct sequencing, returning a total of 33 $\mathrm{kb}$ of sequence (Supplementary Figures. 2-3). Nineteen polymorphic features were identified in the $1.1 \mathrm{~kb}$ sequenced region of the VRN-H1 promoter, while eleven polymorphisms were found in the 1.7 $\mathrm{kb}$ region spanning VRNH1 exon 3 to the 3'UTR. Analysis of the polymorphisms showed all lines belonged to one of the three previously identified VRN-H1 haplotypes, according to the designations described by Cockram et al. (2007b). Alternative varieties Gaelic and SW Alison were found to possess the previously characterized spring VRN-H1 haplotype 5A, with sequencing across the intron I breakpoint confirming that the major deletion detected is identical to the $5.2 \mathrm{~kb}$ deletion found in the spring haplotype 5A variety, 'Golf' (Supplementary Figure 4). Alternative varieties Angela and 52B4 have genotype configurations identical to that of the previously identified haplotype $5 \mathrm{C}$ allele found in 'Express', thought to confer weak vernalization requirement. Sequencing the intron I breakpoint in these alternative SGH varieties showed the location of the $0.5 \mathrm{~kb}$ deletion to be exactly the same as that previously identified in 'Express' (Supplementary Figure 5). The remaining three alternative varieties (Eminant, BR5593C3 and Novetta) displayed the winter 1A haplotype. However, as BR5593C3 and Novetta were shown to carry spring Vrn-H2 alleles, their lack of vernalization requirement is explained by their VRN-H1/VRN-H2 multi-locus haplotype (Table 2). In contrast, the VRN-H1/VRN-H2 multi-locus haplotype of Eminant (1A ? Z) predicted a winter SGH. Although the VRN-H1 multiplex deployed in this study did not detect an intron 1 deletion, it is possible that a previously un-described InDel is present in these varieties. Accordingly, a series of 13 PCR amplicons that tile across the $\sim 11 \mathrm{~kb}$ winter vrn-H1 allele (Cockram et al. 2007b) were used to further investigate intron I configuration in Eminant. PCR amplification was achieved for all but one primer pair: HvBM5a-intron 1-F2/HvBM5a intron 1-R2. This amplicon spans the vernalization critical region (Fu et al. 2005) and suggests the presence of a disruption likely to result in spring SGH. Thus, 
while all six of the alternative varieties investigated were predicted to possess a spring SGH, they possess just one spring allele, either at VRN-H1 or at VRN-H2. 


\section{Discussion}

\section{VRN-H1 haplotypes}

The development of spring varieties during the domestication of barley has been due to the selection of mutated alleles at VRN-H1 and/or VRN-H2. In both instances, these novel alleles are thought to have arisen via insertion-deletion (Cockram et al. 2007b, c, 2011; Fu et al. 2005; von Zitzewitz et al. 2005; Szucs et al. 2007; Hemming et al. 2009). In the case of VRNH1, these rearrangements are thought to disrupt putative cis-regulatory regions within intron I. By overlaying regions of intron I sequence conservation between barley and the related cereal species, wheat (Triticum aestivum L.) with the positions of the major intron I deletions in barley thought to confer spring alleles, putative vernalization critical regions have been identified and refined (Supplementary Figure 1). The first half of intron I ( $\sim 5 \mathrm{~kb}$ ) shows high levels of conservation between these species (Fu et al. 2005). Initially, a $2.8 \mathrm{~kb}$ at the 5 ' end of intron I was identified as possessing particularly high sequence conservations, with the first $436 \mathrm{bp}$ of this region suggested as the region most likely to harbour a 'Triticeae-shared vernalization critical motif' (Fu et al. 2005; von Zitzewitz et al. 2005; Sz \}ucs et al. 2007). Subsequently, expression analyses have highlighted an adjacent $0.5 \mathrm{~kb}$ region associated with high VRN-H1 expression in non-vernalized plants (Hemming et al. 2009). The Eminant VRN-H1 intron I rearrangement identified in this study prevents amplification of a region that spans both the 'vernalization critical' motif and the region associated with high VRN-H1 expression. Given that we failed to amplify across this region in Eminant despite numerous primer pairs being attempted, it may be more likely to represent a large DNA insertion. To date, two instances of transposable element (TE) insertion into Triticeae VRN1 intron I associated with spring alleles are known: a $0.7 \mathrm{~kb}$ insertion 170 bp downstream from the start of intron I in barley [Haplotype 2 (Cockram et al. 2007b), also known as HvVRN1-7 (Hemming et al. 2009)], and a $0.8 \mathrm{~kb}$ TE, inserted $\sim 1 \mathrm{~kb}$ downstream of the start of intron I in Vrn-D1s alleles from the hexaploid wheat species, T. spelta and T. compactum (Muterko et al. 2014). Interestingly, the barley allele carrying the TE insertion has been shown to correlate with the highest level of VRN-H1 expression under unvernalized LD conditions of all alleles studied to date (Hemming et al. 2009; Oliver et al. 2013), indicating that TE insertion may be more effective than deletion in the formation of strong spring Vrn-H1 alleles. Thus, while the precise nature of the intron I rearrangement present in Eminant was not determined, it is very likely to result in a spring Vrn-H1 allele. Controlled environment phenotyping showed that Express, predicted to be a weak winter variety from its VRN-H1/VRN-H2 haplotype (5C ? Z), was under stem extension in SDs, and although significantly later than the late spring control, flowered under LDs. It has been previously noted that the $5 \mathrm{C}$ VRN-H1 allele may confer a weak vernalization response (Cockram et al. 2007b; Hemming et al. 2009). While the vernalization response of Express was not formally investigated here, these results indicate the $5 \mathrm{C}$ allele result in plants that are able to flower in the absence of vernalization. 


\section{Multi-locus haplotypes for SGH and effect on flowering time}

Analysis of the genetic variation at VRN-H1, VRN-H2, PPD-H1 and PPD-H2 allowed the identification of diagnostic multi-locus haplotypes for all three SGH classes. As expected, all winter varieties carried winter alleles at both vernalization loci (vrn-H1/Vrn-H2). In addition, $99 \%$ of winter accessions were predicted to carry recessive ppd-H2 alleles that delay flowering under SDs. This vrnH1/Vrn-H2/ppd-H2 allelic combination presumably helps ensure vegetative growth under winter SD conditions, even after vernalization requirement has been met, thus helping avoid cold damage to reproductive tissues. The three exceptions all had spring varieties in their pedigree, either as one of the parents (Gaulois, Adonis) or grandparents (Tempo). However, allelic state at PPD-H1 was more varied, with an overall ratio of 121:70 LD-responsive versus non-responsive alleles observed. However, when assessed over time, allelic ratios have changed from 2:1 (in years $\leq 1992,1993-1996$ and 1997-2000) to 1:1 (2001-2004) over time (Supplementary Table 3), indicating possible changes in breeder selection for LD photoperiod response over the timescale studied.

The predominance of spring alleles at both VRN-H1 and VRN-H2 in the UK spring varieties investigated is in agreement with previous reports on European germplasm (Cockram et al. 2007b), as is the occurrence of a small minority of spring varieties with allelic combination $\mathrm{Vrn}-\mathrm{H} 1 / \mathrm{Vrn}-\mathrm{H} 2$ (spring/winter). Here, we define a wider multi-locus haplotype for spring barley, in which spring alleles at VRN-H1 are combined with photoperiod insensitive ppd-H1 and Ppd-H2 alleles. This allelic combination would prolong the growth season of spring barley in north-west European conditions, allowing maximum benefit to be gained from the extended growing seasons prevalent in this area. Just one exception to this spring multilocus haplotype was identified (Rebecca), which carried a ppdH2 allele conferring delayed flowering under SDs. Growth room experiments confirmed that Rebecca showed delayed flowering under SDs in comparison with both the early and late spring controls, but was more advanced than all of the alternative varieties investigated, as predicted by its VRNH1/VRN-H1 (spring/winter) haplotype. The majority of varieties carry recessive spring vrn-H2 alleles (ZCCT genes deleted) in combination with wild-type PPD-H2 alleles (HvFT3 present). HvFT3 is normally expressed in SDs only (Faure et al. 2007; Turner et al. 2005). However, in lines lacking VRNH2, HvFT3 is also expressed in LDs (Casao et al. 2011), so it has been suggested that the daylength specificity of HvFT3 might be mediated by VRN-H2 (Fjellheim et al. 2014). Therefore, the predominance of Vrn-H2 alleles in spring varieties may be due to selection of accelerated flowering in LDs due to upregulation of HvFT3.

A diagnostic multi-locus haplotype was also identified for the alternative SGH, characterized by a spring allele at either VRN-H1 or VRN-H2, in combination with mutant ppd-H2 alleles. This multilocus haplotype is predicted to be genetically spring, with delayed flowering under SDs. SDcontrolled environment phenotyping confirmed this, showing that while none of the alternative varieties flowered, all were in stem extension stages by the end of the experiment, and that their developmental stage was intermediate to the winter and late spring controls. Under autumn-sown field 
conditions, the presence of just a single spring vernalization allele combined with ppd- $\mathrm{H} 2$ is assumed to delay reproductive development sufficiently until the onset of LDs in the spring. Autumn planting also means that alternative varieties must be cold hardy. This definition of the alternative SGH agrees with (and expands on) previous genetic descriptions of facultative types, described as having a winter vrn-H1 allele combined with a spring vrn-H2 allele (Karsai et al. 2005; von Zitzewitz et al. 2005). It should be noted that previous investigation of the facultative variety 'Dicktoo' crossed with the winter line 'Komptai Korai' found a flowering time QTL at VRN-H2 (due the spring vrn-H2 allele carried by the facultative parent), while no QTL was identified at PPD-H2 (Karsai et al. 2005). However, this is due to both parents carrying SD insensitive alleles at PPDH2 and agrees with the findings concerning allelic variation at PPD-H2 in winter and alternative/facultative varieties identified here. This limitation raises the importance of exhaustively defining multi-locus flowering time locus haplotypes in the winter and spring germplasm, as well as in alternative/facultative types. Here, we not only identify multi-locus haplotypes for alternative varieties, but also multi-locus haplotypes for large numbers of spring and winter varieties. Indeed, it is this sample size that allows us to highlight the novelty of the observed haplotypes in the alternative lines, even though the alternative type is uncommon (here we include all alternative varieties released in the UK over a 25 -year period). This rarity explains why the alternative type has not previously been well defined genetically. Similarly, such lack of genetic understanding may also, at least partially, explain why they are not often released as varieties. The baseline data provided here will help informed investigation of the effect of currently rare haplotype classes on agronomic traits.

Two major cold hardiness loci have been identified, both on the long arm of chromosome 5H. FROST RESISTANCE-H1 (Fr-H1) is linked to VRN-H1 (von Zitzewitz et al. 2011; Fricano et al. 2009), while Fr-H2 is thought to be encoded by one of the clusters of Crepeat binding factor (CBF) transcription factors that cosegregate with the locus (Francia et al. 2007; Knox et al. 2010). VRN-H1 expression is known to be rapidly and transiently activated after exposure to short periods of cold temperature and is thought to be involved in cold acclimatization pathway leading to frost tolerance (Oliver et al. 2013). VRN-H1 upregulation in response to both short and long exposure to vernalizing temperatures is thought to be modulated by loss of histone $\mathrm{H} 3$ lysine 4 trimethylation (H3K4me3) and increased H3 acetylation (H3Ac) at VRN-H1 chromatin (Oliver et al. 2009, 2013). Interestingly, changes in histone methylation and VRN-H1 upregulation after vernalization are true for both winter (VRN-H1 haplotype 1A) and spring (5A) varieties (Oliver et al. 2009). Indeed, the two regions with the strongest increase in H3Ac (exon I, and at the 50 end of intron I between the VRN-H1 1B and 4A 50 deletion breakpoints) are present in all of the VRN-H1 alleles present in alternative varieties. While all three SGH classes can now be classified using VRN and PPD multi-locus haplotypes, more work is needed to determine the frost tolerance loci and alleles deployed. 


\section{Conclusions}

The ability to track alleles at multiple flowering time loci allows precise manipulation of flowering time and SGH within breeding programmes. Understanding the multi-locus haplotypes underlying alternative SGH allows precise and rapid development of new varieties with the specific flowering time characteristics. Similarly, the wide range of alternative flowering times under LDs in comparison with spring varieties will likely inform future studies aimed at determining the genetic basis behind this. Such knowledge will inform future genetic studies on flowering time, yield and yield components, and help the production of barley for cultivation adapted to a range of agricultural environments. It is likely to be of particular relevance under future climate scenarios predicted by global climate change. 


\section{TABLE LEGENDS}

Table 1. Allelic ratios for four $V R N-H 1, V R N-H 2, P P D-H 1$ and $P P D-H 2(H v F T 3)$ in winter, spring and alternative barley varieties. Wild-type alleles are underlined.SGH (seasonal growth habit).

Table 2. Extended haplotypes for the six alternative varieties, along with the winter varieties Igri and Express (weak vernalization requirement). W (winter), A (alternative), SGH (seasonal growth habit), Mpx (multiplex), del (deletion), $+\mathrm{Z} / \mathrm{Z} Z$ (presence/absence of the three ZCCT genes). ${ }^{\text {a }}$ According to Cockram et al. (2007b). ${ }^{\mathrm{b}} \mathrm{SNP} 22$ (G/T, Turner et al. 2005). ${ }^{\mathrm{c}} 1$ or 0 (presence or absence of HvFT3). ${ }^{\mathrm{d}}$ PCR analysis of intron I finds an unknown rearrangement affecting the vernalization critical region, as delimited by Fu et al. (2005), predicted to result in a spring allele. Alternative $V R N-H I$ intron 1 major deletion nomenclature (Hemming et al. 2009): $0 \mathrm{~kb}$ (HvVRN1), $0.5 \mathrm{~kb}$ (HvVRN1-6) and $5.2 \mathrm{~kb}$ (HvVRN1-1) deletions.

\section{FIGURE LEGENDS}

Figure 1. Diagram of the genomic winter $v r n-H l$ allele from the cultivar 'Strider' (AY750993), indicating the positions of primer used for the $V R N-H l$ multiplex assay (primer pairs 1, 2 and 3, Cockram et al 2009), the (CGCT) SSR in the 5'UTR, SNPs 1 to 3 (promoter), SNP4 and SNP5 (intron 7) and SNP6 (3'UTR). Solid black boxes denote exons. The position of the Lolaog soloLTR within intron I is indicated by the hatched box. The 5.2 $\mathrm{kb}$ intron I deletion characteristic of haplotype $5 \mathrm{~A}$ is indicated by the dashed line box.

Figure 2. The multiplex PCR/agarose-gel genetic marker for HvFT3. The presence/absence of the $873 \mathrm{bp}$ amplicon assays for $H v F T 3$, while the $616 / 574 \mathrm{bp}$ amplicon acts as a positive control, assaying for the 42bp InDel within $V R N-H 1$ intron $1 . \mathrm{L}=1 \mathrm{~kb}$ DNA ladder.

Figure 3. Barley flowering time and development under varying photoperiod. (a) Short-day photoperiod (12 hours). (b) Long-day photoperiod (16 hours). Black, white and grey bars denote winter, spring and alternative varieties, respectively. Standard deviations $(+1)$ for days to flowering are shown. Varieties which did not flower by the end of the experiment are recorded as having a flowering time of 140 days, and their Zadock's growth stage and am example of a main tiller meristem are shown. Ig (Igri), Te (Tremois), Ex (Express), Fe (Felicie), Re (Rebecca), SWA (SW Alison), Ga (Gaelic), No (Novetta). (c) Multi-locus haplotypes at the vernalization loci $V R N-H 1$ and $V R N-H 2$ and photoperiod loci PPD-H2 (responsive to short-days) and $P P D-H I$ (responsive to long days). $1 \mathrm{~A}$ and $5 \mathrm{C}$ haplotypes at $V R N-H 1$ denote winter alleles, all others denote spring. $+\mathrm{Z}$ and $-\mathrm{Z}$ at $V R N-H 2$ denote winter and spring alleles, respectively. $+\mathrm{F}$ and $-\mathrm{F}$ at $P P D-H 2$ denote wild-type and mutated (delayed flowering under short days) alleles at the PPD-H2 candidate gene, HvFT3. (d) Predicted 30 seasonal growth habit, based on multilocus haplotype. W (winter), S (spring), A (alternative), SA (spring-like alternative). 
Table 1

\begin{tabular}{|c|c|c|c|c|c|}
\hline SGH & $\begin{array}{l}\text { Number } \\
\text { of } \\
\text { varieties }\end{array}$ & $\begin{array}{l}\text { Vrn-H1/vrn- } \\
\underline{H 1} \text { allele } \\
\text { frequency }\end{array}$ & $\begin{array}{l}\frac{V r n-H 2 / v r n-}{H 2 \text { allele }} \\
\text { frequency }\end{array}$ & $\begin{array}{l}\frac{P p d-H 1 / p p d-}{H 1 \text { allele }} \\
\text { frequency }\end{array}$ & $\begin{array}{l}H v F T 3 \\
\text { presence / } \\
\text { absence }\end{array}$ \\
\hline Winter & 210 & $0 / 210$ & $210 / 0$ & $121 / 58(\mathrm{U}=26)$ & $3 / 207$ \\
\hline Spring & 170 & $170 / 0$ & $31 / 139$ & $0 / 134(\mathrm{U}=36)$ & $169 / 1$ \\
\hline Alternative & 6 & $2 / 4$ & $3 / 3$ & $2 / 4$ & $0 / 8$ \\
\hline
\end{tabular}

Table 2

\begin{tabular}{|c|c|c|c|c|c|c|c|c|c|c|c|c|c|c|c|}
\hline Variety & SGH & $\begin{array}{l}R N \\
-H 1 \\
\text { Mpx } \\
\end{array}$ & $\begin{array}{c}\text { SNP } \\
1\end{array}$ & $\begin{array}{l}\text { SN } \\
\text { P } 2\end{array}$ & $\begin{array}{c}\text { SNP } \\
3\end{array}$ & SSR & $\begin{array}{c}\text { Intron } \\
1 \text { del. } \\
\text { (kb) }\end{array}$ & $\begin{array}{c}\text { SNP } \\
4\end{array}$ & $\begin{array}{c}\text { SNP } \\
5\end{array}$ & $\begin{array}{c}\text { SNP } \\
6\end{array}$ & $\begin{array}{l}V R N \\
-H 2\end{array}$ & $\begin{array}{l}\text { VRN-H1/ } \\
-H 2 \\
\text { haplotype }^{a}\end{array}$ & $\begin{array}{l}\text { Predicted } \\
\text { SGH }\end{array}$ & $\begin{array}{l}P P D \\
-H 1^{\mathrm{b}}\end{array}$ & $\begin{array}{c}P P D- \\
H 2^{c}\end{array}$ \\
\hline Igri & $\mathrm{W}$ & $1 \mathrm{~A}$ & $\mathrm{~T}$ & $\mathrm{~A}$ & $\mathrm{C}$ & 4 & 0 & $\mathrm{~T}$ & G & $\mathrm{C}$ & $+Z$ & $1 \mathrm{~A}+\mathrm{Z}$ & winter & G & 0 \\
\hline Express & W & $5 \mathrm{C}$ & $\mathrm{T}$ & $\mathrm{G}$ & $\mathrm{C}$ & 5 & 0.5 & $\mathrm{C}$ & $\mathrm{A}$ & G & $+Z$ & $5 C+Z$ & weak winter & $\mathrm{U}$ & $\mathrm{U}$ \\
\hline Eminant & A & $1 \mathrm{~A}^{\mathrm{d}}$ & $\mathrm{T}$ & A & $\mathrm{C}$ & 4 & 0 & $\mathrm{~T}$ & G & $\mathrm{C}$ & $+Z$ & $1 A^{d}+Z$ & spring & $\mathrm{T}$ & 0 \\
\hline BR5593C3 & A & $1 \mathrm{~A}$ & $\mathrm{~T}$ & A & $\mathrm{C}$ & 4 & 0 & $\mathrm{~T}$ & G & $\mathrm{C}$ & $-Z$ & $1 \mathrm{~A}-\mathrm{Z}$ & spring & $\mathrm{T}$ & 0 \\
\hline Novetta & A & $1 \mathrm{~A}$ & $\mathrm{~T}$ & A & $\mathrm{C}$ & 4 & 0 & $\mathrm{~T}$ & G & $\mathrm{C}$ & $-Z$ & $1 \mathrm{~A}-\mathrm{Z}$ & spring & G & 0 \\
\hline $52 \mathrm{~B} 4$ & A & $5 \mathrm{C}$ & $\mathrm{T}$ & $\mathrm{G}$ & $\mathrm{C}$ & 5 & 0.5 & $\mathrm{C}$ & $\mathrm{A}$ & G & $-Z$ & $5 C-Z$ & spring & G & 0 \\
\hline Gaelic & $\mathrm{A}$ & S & $\mathrm{T}$ & $\mathrm{G}$ & $\mathrm{C}$ & 5 & 5.2 & $\mathrm{C}$ & $\mathrm{A}$ & G & $+Z$ & $5 \mathrm{~A}+\mathrm{Z}$ & spring & $\mathrm{T}$ & 0 \\
\hline SW Alison & A & $\mathrm{S}$ & $\mathrm{T}$ & G & $\mathrm{C}$ & 5 & 5.2 & $\mathrm{C}$ & A & G & $+Z$ & $5 A+Z$ & spring & $\mathrm{T}$ & 0 \\
\hline
\end{tabular}

Figure 1

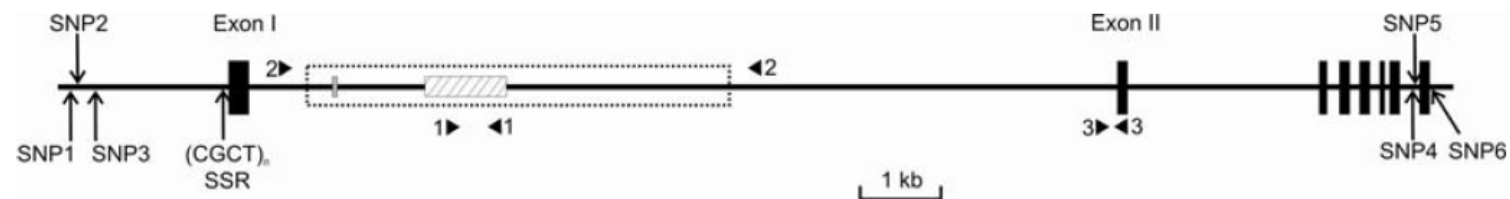

Figure 2

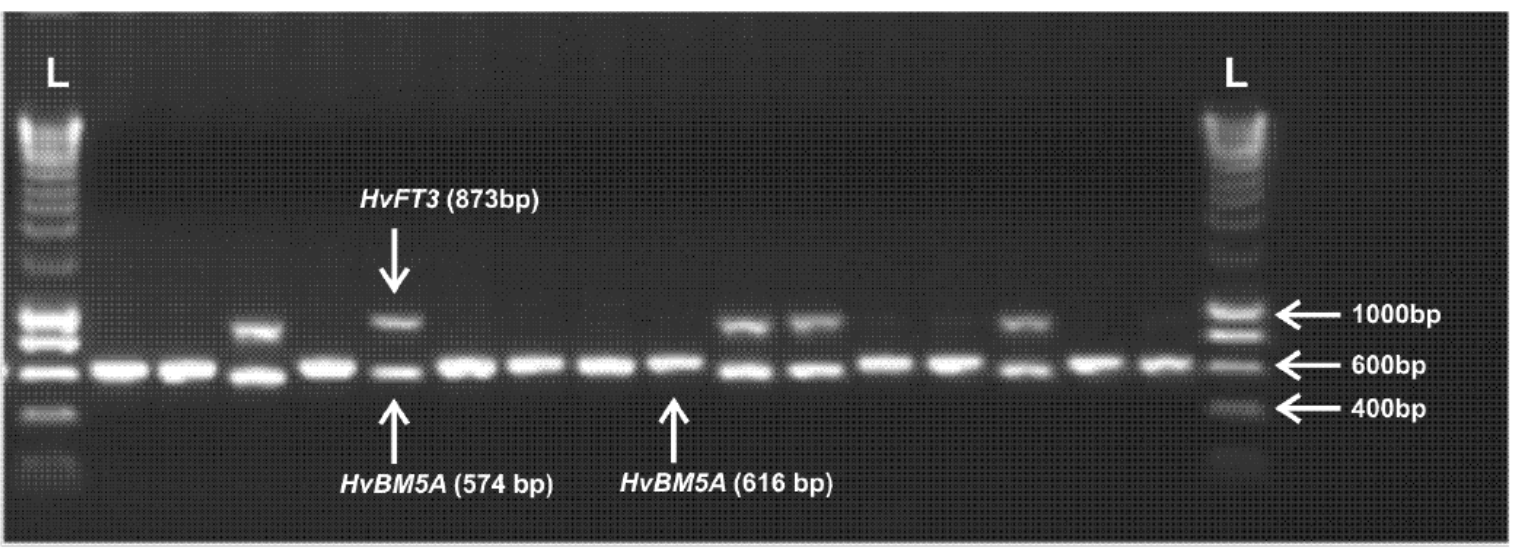


Figure 3

A

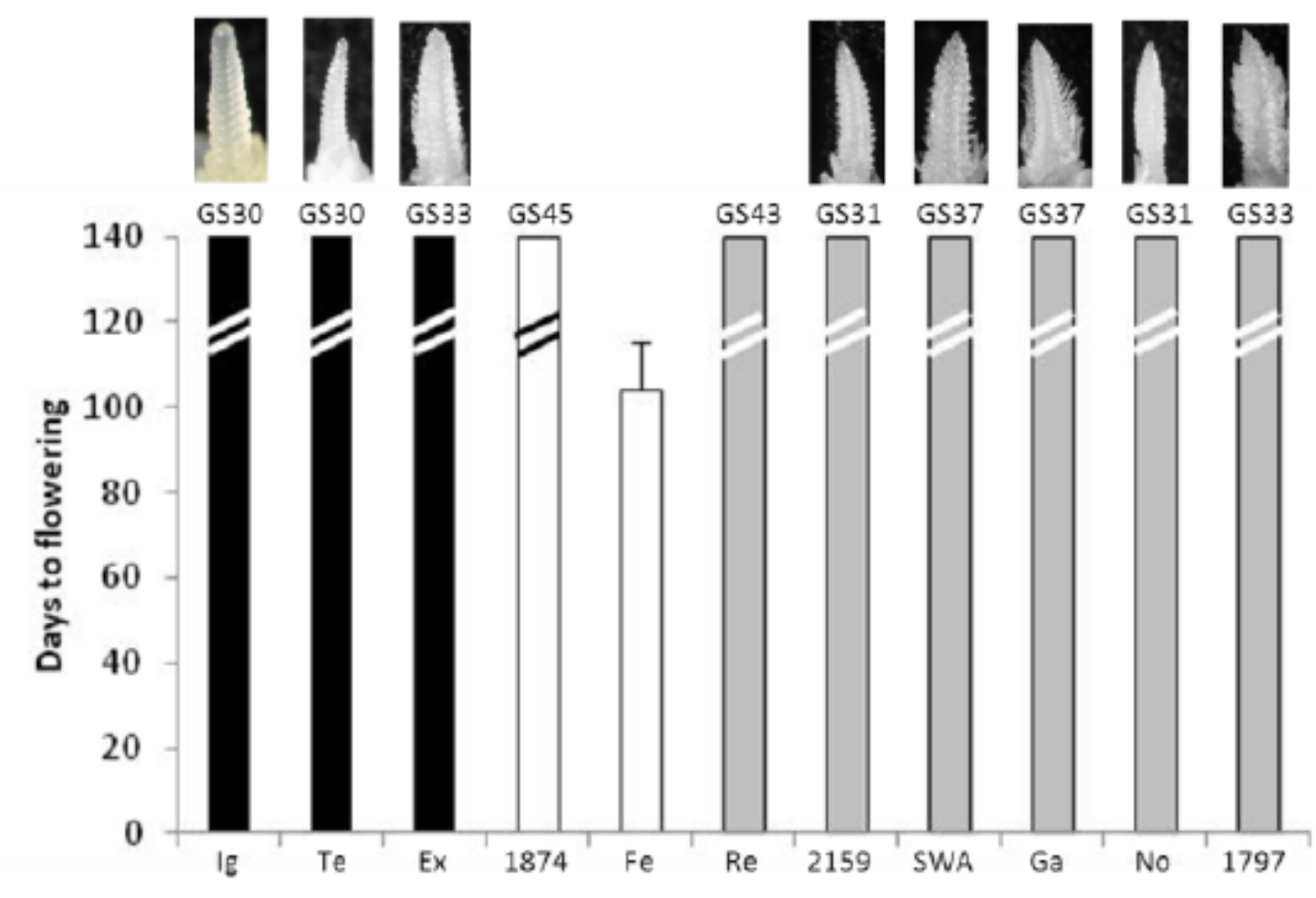

B

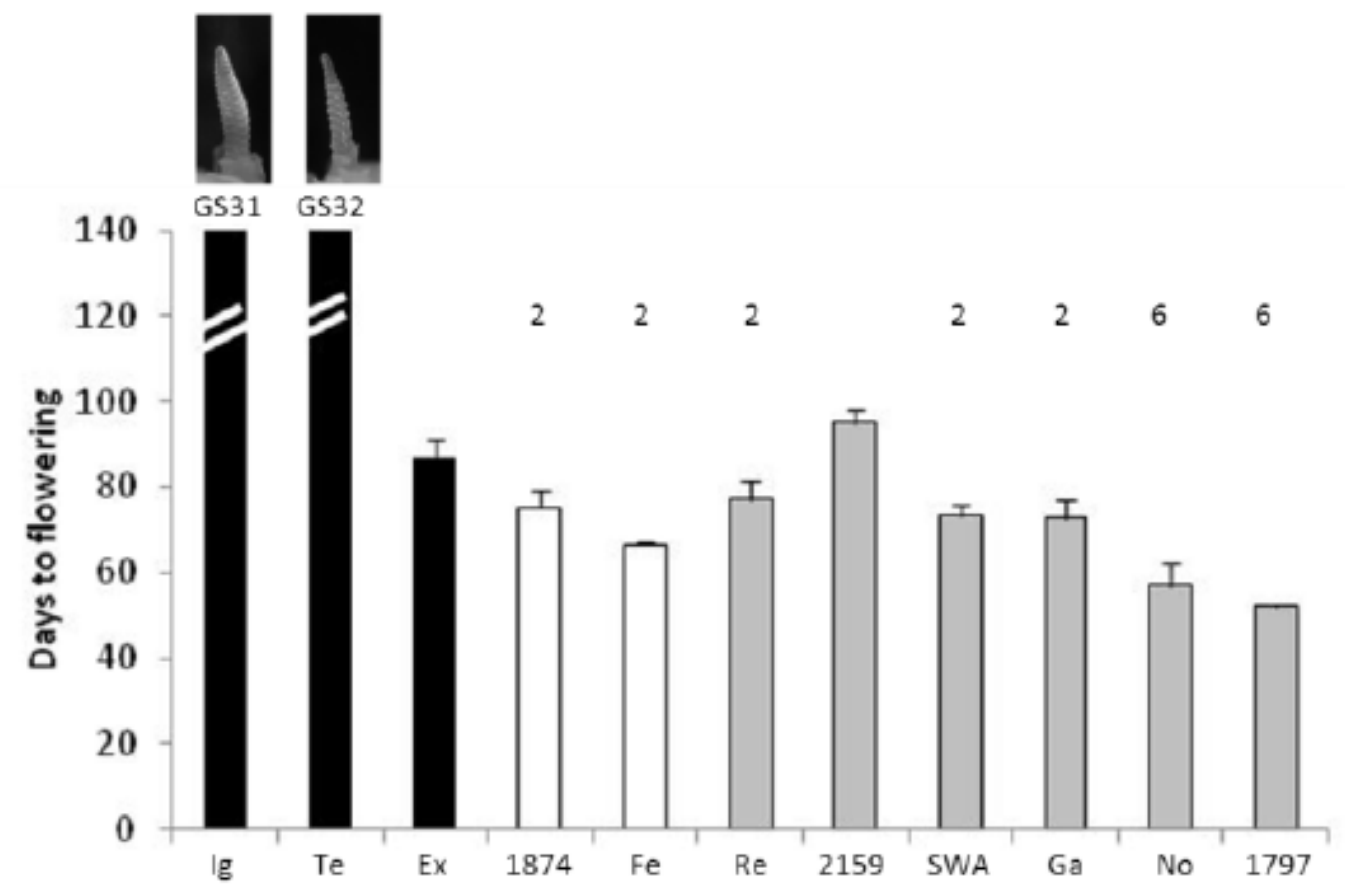

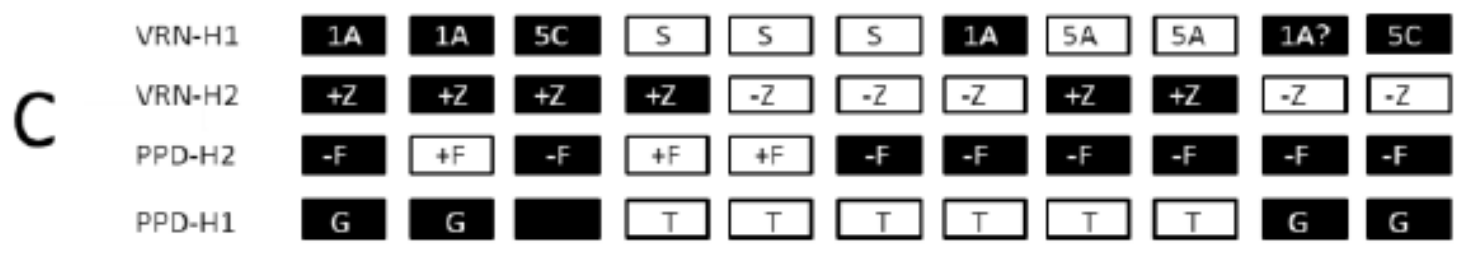

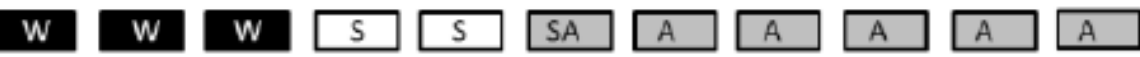

D 
Acknowledgments

This work was funded by Defra Grant

2007J.

\section{Author contributions}

J.C., C.N. and D.O.S. devised research,

J.C., E.S., R.H. undertook experimental work, J.C. analysed data

and wrote the manuscript, all authors reviewed the manuscript. 


\section{References}

Bentley AR, Jensen EF, Mackay IJ, Ho“nicka H, Fladung M, Hori K, Yano M, Mullet JE, Armstead IP, Hayes C, Thorogood D, Lovatt A, Morris R, Pullen N, Mutasa- Gottgens E, Cockram J (2013) Flowering time. In: Cole C (ed) Genomics and breeding for climate-resilient crops, vol 2. Springer, Berlin, pp 1-67 Casao MC, Igartura E, Karsai I, Lasa JU, Gracia MP, Casas AM (2011) Expression analysis of vernalization and day-length response genes in barley (Hordeum vulgare L.) indicates that VRNH2 is a repressor of PPDH2 (HvFT3) under long days. J Exp Bot 62:1939-1949

Cockram J, Jones H, Leigh FJ, O'Sullivan D, Powell W, Laurie DA, Greenland AJ (2007a) Control of flowering time in temperate cereals: genes, domestication and sustainable productivity. J Exp Bot 58:1231-1244

Cockram J, Chiapparino E, Taylor SA, Stamati K, Donini P, Laurie DA, O’Sullivan DM (2007b) Haplotype analysis of vernalization loci in European barley germplasm reveals novel VRN-H1 alleles and a predominant winter VRN-H1/ VRN-H2 multi-locus haplotype. Theor Appl Genet 115:9931001

Cockram J, Mackay IJ, O'Sullivan DM (2007c) The role of double-stranded break repair in the creation of phenotypic diversity at cereal VRN1 loci. Genetics 177:1-5

Cockram J, White J, Leigh FJ, Lea V, Mackay IJ, Laurie DA, Powell W, O’Sullivan DM (2008) Association mapping of partitioning loci in barley. BMC Genet 9:16

Cockram J, Norris C, O'Sullivan DM (2009) PCR-based markers diagnostic for spring and winter seasonal growth habit in barley. Crop Sci 49:403-410

Cockram J, Howells R, O’Sullivan DM (2010a) Segmental duplication harbouring group IV

CONSTANS-like genes in cereals. Genome 53:231-240

Cockram J, White J, Zuluaga DL, Smith D, Comadran J, Macaulay M, Luo Z, Kearsey MJ, Werner P, Harrap D et al (2010b) Genome-wide association mapping to candidate polymorphism resolution in the unsequenced barley genome. Proc Natl Acad Sci USA 107:21611-21616

Cockram J, Jones H, O'Sullivan DM (2011) Genetic variation at flowering time loci in wild and cultivated barley. Plant Genet Res Charact Utili 9:264-267

Cockram J, Thiel T, Steuernagel B, Stein N, Taudien S, Bailey PC, O'Sullivan DM (2012a) Genome dynamics explain the evolution of flowering time CCT domain gene families in the Poaceae. PLoS ONE 7:e45307

Cockram J, Jones H, Norris C, O'Sullivan DM (2012b) Evaluation of diagnostic molecular markers for DUS phenotypic assessment in the cereal crop, barley (Hordeum vulgare ssp. vulgare L.). Theor Appl Genet 125:1735-1749

Distelfeld A, Tranquilli G, Li C, Yan L, Dubcovsky J (2009) Genetic and molecular characterization of the VRN2 loci in tetraploid wheat. Plant Physiol 149:245-257

Faure S, Higgins J, Turner A, Laurie DA (2007) The FLOWERING LOCUS-T-like family in barley (Hordeum vulgare). Genetics 176:599-609 
Fjellheim S, Boden S, Trevaskis B (2014) The role of seasonal flowering responses in adaptation of grasses to temperate climates. Front Plant Sci 4:431

Francia E, Rizza F, Cativelli L, Stanca AM, Busconi M, Fogher C, Stockinger EJ, Pecchioni N (2007) Fine mapping of a $\mathrm{HvCBF}$ gene cluster at the frost resistance locus Fr-H2 in barley. Theor Appl Genet 115:1083-1091

Fricano A, Rizza F, Faccioli P, Pagani D, Pavan P, Stella A, Rossini L, Piffanelli P, Cattivelli L (2009) Genetic variants of HvCBF14 are statistically associated with frost tolerance in an European germplasm collection of Hordeum vulgare. Theor Appl Genet 119:1335-1348

Fu D, Szucs P, Yan L, Helguera M, Skinner JS, von Zitzewitz J, Hayes PM, Dubcovsky J (2005) Large deletions within the first intron in VRN-1 are associated with spring growth habit in barley and wheat. Mol Genet Genomics 273:54-65

Hemming MN, Fieg S, Peacock WJ, Dennis ES, Trevaskis B (2009) Regions associated with repression of the barley (Hordeum vulgare) VERNALIZATION1 gene are not required for cold induction. Mol Genet Genomics 282:107-117

Jones H, Civan P, Cockram J, Leigh FJ, Smith LMJ, Jones MK, Charles MP, Molina-Cano J-L, Powell W, Jones G, Brown TA (2011) Evolutionary history of barley cultivation in Europe revealed by genetic analysis of extant landraces. BMC Evol Biol 11:320

Jones H, Norris C, Cockram J, Lee D (2013) Variety protection and plant breeders' rights in the 'DNA era'. In: Lubberstedt T, Varshney RK (eds) Diagnostics in plant breeding. Springer,

Netherlands, pp 396-402

Karsai I, Sz\} ucs P, Me’sza'ros K, Filichkina T, Hayes PM, Skinner JS, La'ng L, Bedo“ Z (2005) The Vrn-H2 locus is a major determinant of flowering time in a facultative $\mathrm{X}$ winter growth habit barley (Hordeum vulgare L.) mapping population. Theor Appl Genet 110:1458-1466

Knox AK, Dhillon T, Cheng H, Tondelli A, Pecchioni N, Stockinger EJ (2010) CBF gene copy number variation at Frost Resistance-2 is associated with levels of freezing tolerance in temperateclimate cereals. Theor Appl Genet 121:21-35

Laurie DA, Pratchett N, Bezant JH, Snape JW (1995) RFLP mapping of five major genes and eight quantitative trait loci controlling flowering time in a winter x spring barley (Hordeum vulgare L.) cross. Genome 38:575-585

Muterko A, Balashova I, Cockram J, Kalendar R, Sivolap Y (2014) The wheat vernalization response allele Vrn-D1s is caused by DNA transposon insertion in the first intron. Plant Mol Biol Rep. doi:10.1007/s11105-014-0750-0

Oliver SN, Finnegan EJ, Dennis ES, Peacock WJ, Trevaskis B (2009) Vernalization-induced flowering in cereals is associated with changes in histone methylation at the VERNALIZATION1 gene. Proc Natl Acad Sci USA 106:8386-8391 
Oliver SN, Deng W, Casao C, Trevaskis B (2013) Low temperatures induce rapid changes in chromatin state and transcript levels of the cereal VERNALIZATION1 gene. J Exp Bot 64:24132422

Szucs P, Skinner J, Karsai I, Cuesta-Marcos A, Haggard KG, Corey AE, Chenn THH, Hayes PM (2007) Validation of the VRN-H2/VRN-H1 epistatic model in barley reveals that intron length variation at VRN-H1 may account for a continuum of vernalization sensitivity. Mol Genet Genomics 277:249-261

Thompson JD, Higgins DG, Gibson TJ (1994) CLUSTAL W: improving the sensitivity of progressive multiple sequence alignment through sequence weighting, position specific gap penalties and weight matrix choice. Nucleic Acids Res 22:4673-4680

Trevaskis B (2010) The central role of the VERNALIZATION1 gene in the vernalization response of cereals. Funct Plant Biol 37:479-487

Trevaskis B, Hemming MN, Peacock WJ, Dennis ES (2006) HvVRN2 responds to day length, whereas HvVRN1 is regulated by vernalization and developmental status. Plant Physiol 140:13971405

Turner A, Beales J, Faure S, Dunford RP, Laurie DA (2005) The pseudo-response regulator Ppd-H1 provides adaptation to photoperiod in barley. Science 310:1031-1034

Turner AS, Faure S, Zhang Y, Laurie DA (2013) The effect of day-neutral mutations in barley and wheat on the interaction between photoperiod and vernalization. Theor Appl Genet 126:2267-2277 von Zitzewitz J, Sz\}ucs P, Dubcovsky J, Yan L, Francia E, Pecchioni N, Casas A, Chen THH, Hayes PM, Skinner JS (2005) Molecular and structural characterization of barley vernalization genes. Plant Mol Biol 59:449-467

von Zitzewitz J, Cuesta-Marcos A, Condon F, Castro AJ, Chao S, Corey A, Filichkin T, Fisk SP, Gutierrez L, Haggard K et al (2011) The genetics of winterhardiness in barley: perspectives from genome-wide association mapping. Plant Genome 4:76-91

Xue W, Xing Y, Weng X, Zhao Y, Tang W et al (2008) Natural variation in Ghd7 is an important regulator of heading date and yield potential in rice. Nat Genet 40:761-767

Yan L, Loukoianov A, Blechl A, Tranquilli G, Ramakrishna W, SanMiguel P, Bennetzen JL, Echenique V, Dubcovsky J (2004) The wheat VRN2 gene is a flowering repressor downregulated by vernalization. Science 303:1640-1644 